\title{
XÁC ĐịNH ĐỔNG THỜI MộT SỐ DẬNG CỦA VITAMIN NHÓM B TRONG SẢN PHẨM DINH DƯỡNG BẰNG KỸ THUÂTT SẮC KÝ LỎNG KHỐI PHỔ (LC-MS/MS) SAU THƯYY PHÂN ENZYME
}

\author{
Lê Thị Thúy ${ }^{I^{*}}$, Vũ Thị Trang ${ }^{\prime}$, Trần Hoàng Giang', Trần Mai Vân', Lê Thị Hồng Hảol \\ IViện Kiểm nghiệm ATVSTP Quốc Gia \\ ${ }^{2}$ Trưòng Đại học Y Hà Nội
}

(Ngày đến tòa soạn: 2/1/2019; Ngày sủa bài sau phản biện: 14/2/2019; Ngày chấp nhận đăng: 22/2/2019)

\section{Tóm tắt}

Dhương pháp sắc ký lỏng ghép nối khối phổ được sử dụng để định lượng đồng thời một số dạng của vitamin nhóm B gồm: vitamin B1, vitamin B2, vitamin B3, vitamin B6 trong các sản phẩm thực phẩm dinh dưỡng. Mẫu được thủy phân sử dụng hỗn hợp 3 loại enzyme (enzyme papain, $\alpha$-amylase để thủy phân protenin và carbonhydrat phức tạp, enzyme phosphatase để thủy phân các liên kết phosphoryl) tại nhiệt độ $37^{\circ} \mathrm{C}$ trong khoảng $12-14$ h trong bể lắc ổn nhiệt. Việc tách các vitamin được thực hiện trên cột sắc ký pha đảo $\mathrm{C} 18(100 \mathrm{~mm} \times 2,1 \mathrm{~mm} \times 1,7 \mu \mathrm{m})$ và tiền cột tương ứng, pha động gồm dung dịch amoni format $10 \mathrm{mM}$ và $\mathrm{MeOH}$ theo chương trình rửa giải gradient.

Tốc độ dòng $0,15 \mathrm{ml}$ /phút, detector khối phổ chế độ ESI $(+)$. Đường chuẩn được xây dựng trong khoảng 0,2-2000 ng/mL với hệ số tương quan $\left(\mathrm{R}^{2}\right)>0,998$. Giới hạn phát hiện $(\mathrm{LOD})$ và giới hạn định lượng (LOQ) của phương pháp tương ứng trong khoảng từ 2,7-3,8 $\mu \mathrm{g} / 100 \mathrm{~g}$ và 9,1 - 12,6 $\mu \mathrm{g} / 100 \mathrm{~g}$. Độ thu hồi của phương pháp trong khoảng 80 - 110\% với độ lệch chuẩn tương ứng của độ lặp lại $\left(\mathrm{RSD}_{\mathrm{r}} \%\right)$ trong khoảng 2,61 - 4,69\% và độ tái lập $\left(\mathrm{RSD}_{\mathrm{R}} \%\right)$ trong khoảng 3,40 - 9,69\%. Phương pháp có độ nhạy, độ chọn lọc cao được ứng dụng để phân tích một số nền mẫu thực phẩm dinh dưỡng.

Tù khóa: Vitamin, LC-MS/MS, sản phẩm dinh dương

\section{I. ĐÅT VẤN ĐỀ}

Vitamin nhóm $\mathrm{B}$ là những hợp chất hữu cơ tan trong nước, có trọng lượng phân tử bé, có hoạt tính sinh học tham gia vào các phản ứng enzyme, các quá trình trao đổi chất nhằm chuyển hóa cơ chất thành năng lượng cần thiết cho cơ thể. Trong thực phẩm vitamin nhóm $\mathrm{B}$ tồn tại ở cả dạng tự do và dạng liên kết phức tạp. Hơn nữa, cơ thể không tự tổng hợp được mà phải thu nhận từ thức ăn. Nhu cầu vitamin trong cơ thể thường được đảm bảo nhờ chế độ ăn uống cân bằng, khi cơ thể thiếu hoặc dư thừa vitamin gây nên bệnh lý ảnh hưởng đến sức khỏe. Vì vậy, việc bổ sung đầy đủ và cân đối các vitamin là cần thiết. Do đó, bên cạnh việc sử dụng các sản phẩm thực phẩm thông thường người tiêu dùng đang có xu hướng tìm đến các sản phẩm thực phẩm bổ sung giàu vi chất dinh dưỡng trong đó có các vitamin nhóm $\mathrm{B}$. Việc xây dựng phương pháp để định lượng chính xác các thành phần này trong thực phẩm nói chung và thực phẩm dinh dưỡng nói riêng là cần thiết nhằm đánh giá chất lượng của sản phẩm, giúp cho người tiêu dùng an tâm khi sử dụng và giúp cho nhà quản lý có cơ sở để kiểm soát chất lượng của các sản phẩm này. 
Có rất nhiều các phương pháp khác nhau được sử dụng để định lượng vitamin nhóm $\mathrm{B}$ trong thực phẩm [1-5, 7-10]. Tuy nhiên, hạn chế của các phương pháp là chỉ xác định được nhóm vitamin dạng tự do hoặc định lượng được từng vitamin đơn lẻ mà không xác định được đồng thời tất cả các dạng khác nhau của mỗi vitamin. Quy trình phân tích khá phức tạp đòi hỏi quá trình dẫn xuất trước hoặc sau cột. Hơn nữa, trong các nền mẫu thực phẩm có chứa các thành phần vitamin như (pyridoxal, pyridoxamin, acid nicotinic) có hàm lượng thấp nên việc sử dụng kỹ thuật sắc ký lỏng hiệu năng cao (HPLC) chưa đáp ứng được độ nhạy để xác định các chất này.

Vì vậy, trong nghiên cứu này chúng tôi tiến hành phân tích đồng thời các dạng khác nhau của một số loại vitamin B1, B2, B3, B6 sử dụng kỹ thuật sắc ký lỏng khối phổ kết hợp với sử dụng hỗn hợp các enzyme như: enzyme papain, $\alpha$-amylase, acid phosphatase để phân cắt các liên kết phức tạp trong nền mẫu đồng thời tiến hành thủy phân đồng thời cả chuẩn và mẫu phân tích kết hợp với sử dụng các nội chuẩn đồng vị và phân tích trên hệ thống sắc ký lỏng khối phổ (LC-MS/MS). Do đó có thể tách và định lượng được đồng thời tổng các dạng khác nhau của vitamin và loại bỏ được các yếu tố ảnh hưởng đến quá trình thủy phân. Phương pháp có độ nhạy, độ chọn lọc và độ tin cậy cao phù hợp để phân tích các hoạt chất có hàm lượng thấp.

\section{II. ĐỐI TƯợNG VÀ PHU’ƠNG PHÁP NGHIÊN CÚU}

Chất chuẩn, hóa chất: Chất chuẩn Thiamin.HCl, Riboflavin, Nicotinamide, nicotinic acid, Pyridoxine hydrochloride, Pyridoxamine dihydrochloride, Pyridoxal hydrochloride (Sigma). Nội chuẩn: ${ }^{13} \mathrm{C}_{4}$-Thiamine chloride, ${ }^{13} \mathrm{C}_{4}{ }^{15} \mathrm{~N}_{2}$-Riboflavin, ${ }^{2} \mathrm{H}_{4}$-Nicotinamide, ${ }^{2} \mathrm{H}_{4}$-Nicotinic acid, ${ }^{13} \mathrm{C}_{4}$-Pyridoxine, ${ }^{2} \mathrm{H}_{3}$-Pyridoxal, ${ }^{2} \mathrm{H}_{3}$-Pyridoxamine (IsoSience). Các loại hóa chất, thuốc thử tinh khiết phân tích và đạt yêu cầu cho phân tích LC-MS/MS (amoni format, methanol, acid formic, acid acetic, enzyme papain, $\alpha$-amylase, phosphatase, ethylenediaminetetracetic acid disodium salt dihydrate (EDTA), dikali hydrogen phosphat, acid metaphosphoric, acid orthophosphoric, $\mathrm{KOH}$, chuẩn $\mathrm{pH} 4,7,10$ ). Hỗn hợp enzyme (amylase, protease, acid phosphatase) được chuẩn bị như sau: Cân chính xác $200 \pm 10$ $\mathrm{mg}$ acid phosphatase, $80 \pm 5 \mathrm{mg}$ enzyme $\alpha$-amylase và $400 \pm 10 \mathrm{mg}$ enzyme papain. Thêm $200 \mathrm{ml}$ dung dịch ammoni format. Khuấy đều khoảng 10 phút trên máy khuấy từ gia nhiệt. Điều chỉnh $\mathrm{pH}$ tới 4,0 - 4,5 bằng acid formic (khoảng $100 \mu \mathrm{L}$ ).

Thiết bị: Hệ thống sắc ký lỏng khối phổ khối phổ LC/MS/MS Xevo TQD (Waters). Cột phân tích Waters Acquity BEH C18 (2,1 x 100mmx 1,7 ìm và tiền cột tương ứng.

Đối tượng phân tích: Một số mẫu thực phẩm dinh dưỡng (sữa bột, sữa dạng lỏng, bột dinh dưỡng) được thu thập ngẫu nhiên trên địa bàn Hà Nội.

\section{Quy trìh xừ lý mẫu:}

Mẫu được đồng nhất kỹ trước khi phân tích. Đối với mẫu dạng bột, cần thực hiện hoàn nguyên mẫu như sau: cân $10 \pm 0,3 \mathrm{~g}$ mẫu vào bình chứa. Thêm nước cất để được tổng khối lượng $100 \pm 2 \mathrm{~g}$. Tiến hành khuấy đều trên máy khuấy từ. Cân chính xác khoảng 0,25-1g mẫu lỏng hoặc mẫu bột đã hoàn nguyên vào ống ly tâm $50 \mathrm{~mL}$. Thêm $100 \mu$ l nội chuẩn hỗn hợp vào cả chuẩn làm việc và mẫu phân tích, lắc đều. Thêm tiếp $5 \mathrm{~mL}$ hỗn hợp enzyme vào tất cả các dung dịch chuẩn làm việc và mẫu. Đậy nắp và lắc vortex ngay lập tức. Tiến hành ủ qua đêm ở $37^{\circ} \mathrm{C}$ trong máy lắc ổn nhiệt. Chuẩn và mẫu sau khi được thủy phân được chuyển vào bình định mức $25 \mathrm{~mL}$ và định mức tới vạch bằng dung dịch ammoni format $50 \mathrm{mM}$, lắc đều. Lọc qua màng lọc PTFE $0,45 \mu \mathrm{m}$. Dịch lọc được phân tích trên hệ thống UPLC-MS/MS.

\section{KẾT QUẢ VÀ BÀN LUẬN}

\subsection{Khảo sát điều kiện tách và định lượng vitamin nhóm $B$ trên thiết bị LC-MS/MS}

Sử dụng chế độ ion hóa phun điện tử ESI dương và tối ưu hóa tự động điều kiện phân mảnh trên hệ thống sắc ký lỏng khối phổ Xevo TQD (Waters). Kết quả tối ưu điều kiện phân tích các vitamin nhóm $\mathrm{B}$ được thể hiện trong bảng 1 . 
Bảng 1. Các thông số tối ưu hóa điè̀u kiện phân mảnh trên UPLC-MS/MS

\begin{tabular}{|c|c|c|c|c|}
\hline Chất phân tích & Ion mẹ & Ion con & Thếion hóa (V) & $\begin{array}{l}\text { Năng lự̆ng bắn phá } \\
\text { (V) }\end{array}$ \\
\hline Nicotinamide* & \multirow{2}{*}{123} & 80 & 44 & 16 \\
\hline Nicotinamide & & 96 & 44 & 18 \\
\hline${ }^{2} \mathrm{H}_{4}$-Nicotinamide* & \multirow{2}{*}{127} & 84 & 44 & 18 \\
\hline${ }^{2} \mathrm{H}_{4}$-Nicotinamide & & 100 & 44 & 18 \\
\hline Nicotinic Acid* & \multirow{2}{*}{124} & 80 & 40 & 20 \\
\hline Nicotinic Acid & & 106 & 40 & 20 \\
\hline${ }^{2} \mathrm{H}_{4}$-Nicotinic Acid* & \multirow{2}{*}{128} & 84 & 44 & 16 \\
\hline${ }^{2} \mathrm{H}_{4}$-Nicotinic Acid & & 109 & 44 & 16 \\
\hline Pyridoxal & \multirow{2}{*}{168} & 94 & 24 & 22 \\
\hline Pyridoxal* & & 150 & 24 & 12 \\
\hline${ }^{2} \mathrm{H}_{3}$-Pyridoxal & \multirow{2}{*}{171} & 97 & 22 & 24 \\
\hline${ }^{2} \mathrm{H}_{3}$-Pyridoxal* & & 153 & 22 & 12 \\
\hline Pyridoxamine & \multirow{2}{*}{169} & 134 & 24 & 20 \\
\hline Pyridoxamine* & & 152 & 24 & 12 \\
\hline${ }^{2} \mathrm{H}_{3}$-Pyridoxamine & \multirow{2}{*}{172} & 136 & 26 & 20 \\
\hline${ }^{2} \mathrm{H}_{3}$-Pyridoxamine* & & 155 & 26 & 14 \\
\hline Pyridoxine* & \multirow{2}{*}{170} & 134 & 30 & 20 \\
\hline Pyridoxine & & 152 & 30 & 13 \\
\hline${ }^{13} \mathrm{C}_{4}$-Pyridoxine* & \multirow{2}{*}{174} & 138 & 28 & 20 \\
\hline${ }^{13} \mathrm{C}_{4}$-Pyridoxine & & 156 & 28 & 12 \\
\hline Thiamine & \multirow{2}{*}{265} & 81 & 20 & 30 \\
\hline Thiamine* & & 122 & 24 & 34 \\
\hline${ }^{13} \mathrm{C}_{4}$-Thiamine & \multirow{2}{*}{269} & 81 & 24 & 28 \\
\hline${ }^{13} \mathrm{C}_{4}$-Thiamine* & & 122 & 22 & 16 \\
\hline Riboflavin & \multirow{2}{*}{377} & 198 & 34 & 38 \\
\hline Riboflavin* & & 243 & 34 & 22 \\
\hline${ }^{13} \mathrm{C}_{4},{ }^{15} \mathrm{~N}_{2}$ Riboflavin & \multirow{2}{*}{383} & 175 & 44 & 38 \\
\hline${ }^{13} \mathrm{C}_{4},{ }^{15} \mathrm{~N}_{2}$ Riboflavin* & & 249 & 44 & 22 \\
\hline
\end{tabular}




\section{* Mảnh định lương}

Trong LC/MS, pha động không chỉ có ảnh hưởng đến khả năng rửa giải và phân tách các chất phân tích mà nó còn ảnh hưởng tới quá trình ion hóa. Qua tham khảo tài liệu [6], thành phần pha động được lựa chọn gồm muối amoni format và methanol. Kết quả nghiên cứu cho thấy, tín hiệu chất phân tích thu được cao nhất khi sử dụng nồng độ đệm amoni format $5 \mathrm{mM}$ và thay đổi không đáng kể khi tăng nồng độ đến $10 \mathrm{mM}$. Tuy nhiên, khi tiếp tục tăng nồng độ dung dịch đệm lên $20 \mathrm{mM}$ và $50 \mathrm{mM}$ tín hiệu chất phân tích giảm do khi nồng độ muối cao, làm tăng số lượng ion đi vào buồng ion của detector MS do đó làm cạnh tranh với ion chất phân tích, làm giảm tín hiệu của các chất phân tích. Khi sử dụng nồng độ đệm amoni format $5 \mathrm{mM}$ tín hiệu chất phân tích của vitamin $\mathrm{B} 2$ và vitamin $\mathrm{B} 6$ (pyridoxamin, pyridoxal) bị doãng, pic bị tù, bị kéo đuôi. Tại nồng độ $10 \mathrm{mM}$ tất cả các vitamin nhóm $\mathrm{B}$ cho tín hiệu chất phân tích nhọn, cân đối. Vì vậy, chúng tôi lựa chọn nồng độ đệm amoni format là $10 \mathrm{mM}$ để rửa giải các chất phân tích, nồng độ này cũng phù hợp với các hệ LC/MS/MS.

\subsection{Khảo sát quy trình chiết mẫu}

Trong nền mẫu thực phẩm nói chung và sản phẩm dinh dưỡng nói riêng, các vitamin tồn tại ở cả dạng tự do và các dạng liên kết phức tạp. Việc sử dụng phương pháp enzyme để phân cắt các liên kết trong cấu trúc của các vitamin được ưu tiên lựa chọn. Trong nghiên cứu này, chúng tôi đã sử dụng hỗn hợp 3 loại enzyme (enzyme amylase bền nhiệt thủy phân tinh bột và đường, enzyme protease thủy phân protein và enzyme phosphatase để thủy phân các liên kết phosphat).

Kết quả khảo sát ảnh hưởng của nồng độ dung dịch đệm trong khoảng 5-100 mM đến khả năng hoạt động của enzyme được thể hiện trong hình 1.

Khi thay đổi nồng độ dung dịch amoni format, lượng chất phân tích thu được tăng dần và cao nhất tại nồng độ $50 \mathrm{mM}$. Tuy nhiên, khi nồng độ đệm tăng đến $100 \mathrm{mM}$, lượng chất phân tích thu

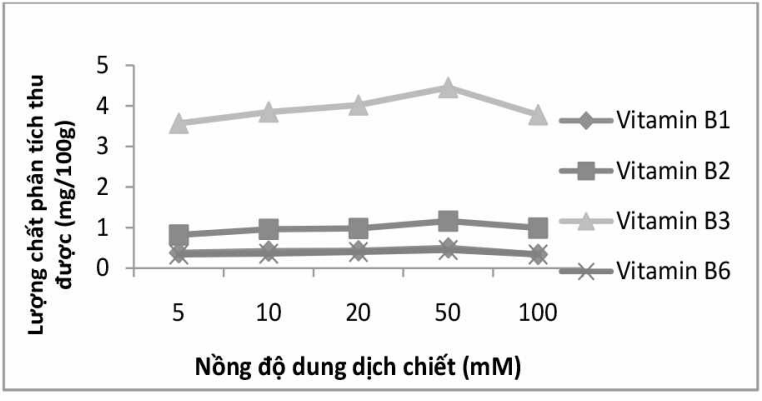

Hình 1. Đồ thị khảo sát ảnh huoơng nồng độ dung dịch chiết mẫu được giảm xuống có thể do sự canh tranh ion. Do đó, nồng độ đệm amoni format $50 \mathrm{mM}$ được lựa chọn tối ưu.

Nhiệt độ có ảnh hưởng tới hoạt độ của enzyme, khi nhiệt độ cao hơn nhiệt độ tối ưu, tốc độ phản ứng giảm nhanh, trung tâm hoạt động mất đi cấu hình chuẩn và không còn phù hợp được với cơ chất, do đó làm mất vai trò xúc tác của enzyme. Nếu nhiệt độ thấp, tốc độ phản ứng chậm, hiệu quả thủy phân thấp. Tham khảo một số tài liệu [1], [2], [6], [7], tiến hành khảo sát nhiệt độ thủy phân tại các mức: $35^{\circ} \mathrm{C}, 37^{\circ} \mathrm{C}, 40^{\circ} \mathrm{C}, 45^{\circ} \mathrm{C}, 50^{\circ} \mathrm{C}$ cho thấy: Lượng chất phân tích thu được tăng lên khi nhiệt độ từ 35 đến $37^{\circ} \mathrm{C}$ và thay đổi không đáng kể khi nhiệt độ thủy phân tăng $40^{\circ} \mathrm{C}$. Tuy nhiên, nếu tiếp tục tăng nhiệt độ thủy phân đến $45-50^{\circ} \mathrm{C}$, thì lượng chất phân tích thu được giảm xuống. Vì vậy nhiệt độ $37^{\circ} \mathrm{C}$ được lựa chọn do hàm lượng các chất phân tích thu được cao nhất. Đây cũng là nhiệt độ tối ưu để enzyme hoạt động xúc tác cho quá trình thủy phân mẫu.

Thời gian thủy phân mẫu có ảnh hưởng đến khả nãng tương tác của enzym với cơ chất phân 
tích. Qua tham khảo một số tài liệu [1], [2], [6], [7] các khoảng thời gian được lựa chọn để khảo sát gồm: $3 \mathrm{~h}, 6 \mathrm{~h}, 9 \mathrm{~h}, 12 \mathrm{~h}, 14 \mathrm{~h}, 16 \mathrm{~h}$. Kết quả khảo sát được chỉ ra trong hình 2.

Khi thay đổi thời gian thủy phân (3-12h) lượng chất phân tích thu được cũng tăng dần và thay đổi không đáng kể khi tiếp tục tăng thời gian thủy phân đến 14 h. Tuy nhiên nếu tiếp tục tăng thời gian thủy phân 16h, lượng chất phân tích thu được bắt đầu giảm có thể do sự phân hủy của chất phân tích. Do đó, thời gian được lựa chọn để thủy phân mẫu trong khoảng 12-14h.

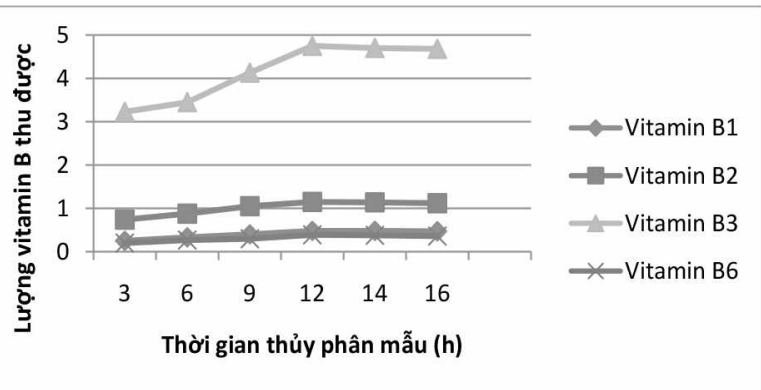

Hình 2. Đồ thị khảo sát ảnh hưởng của thời gian thưy phân

\section{3. Đánh giá phương pháp phân tích}

\subsubsection{Xây dựng đường chuẩn}

Đường chuẩn được xây dựng trong khoảng $0,2-2000 \mathrm{ng} / \mathrm{mL}$ (tùy thuộc vào từng vitamin). Kết quả phân tích trong bảng 2 cho thấy hệ số tương quan $\mathrm{R}^{2}>0,998$, độ chệch bias $<( \pm) 15 \%$. Các thông số của đường chuẩn đạt yêu cầu.

Bảng 2. Phương trình đi̛ờng chuẩn của các vitamin

\begin{tabular}{|c|l|c|c|c|}
\hline TT & Chất phân tích & Phuơng trình đuoòng chuẩn & $\begin{array}{c}\text { Hệ số tuơng quan } \\
\text { hồi quy } \boldsymbol{R}^{2}\end{array}$ & $\begin{array}{c}\text { Độ chệch Bias } \\
\text { (\%) }\end{array}$ \\
\hline 1 & Thiamin & $\mathrm{y}=1,19585 \mathrm{x}+0,752474$ & 0,999282 & $-5,6 \div 5,7$ \\
\hline 2 & Riboflavin & $\mathrm{y}=0,93746 \mathrm{x}+4,66988$ & 0,998967 & $-6,3 \div 7,2$ \\
\hline 3 & Niacinamide & $\mathrm{y}=1,82501 \mathrm{x}+6,58545$ & 0,999463 & $-3,9 \div 5,4$ \\
\hline 4 & Acid nicotinic & $\mathrm{y}=1,17805 \mathrm{x}+0,959455$ & 0,998424 & $-3,9 \div 5,5$ \\
\hline 5 & Pyridoxin & $\mathrm{y}=1,63385 \mathrm{x}+0,520011$ & 0,999170 & $-4,2 \div 5,0$ \\
\hline 6 & Pyridoxal & $\mathrm{y}=3,19964 \mathrm{x}+0,38554$ & 0,999194 & $-3,6 \div 4,0$ \\
\hline 7 & Pyridoxamin & $\mathrm{y}=12,122 \mathrm{x}+0,75241$ & 0,999385 & $-2,6 \div 4,9$ \\
\hline
\end{tabular}

\subsubsection{Giới hạn phát hiện (LOD), giới hạn định lương ( $L O Q)$}

Trên nền mẫu thực phẩm dinh dưỡng có hàm lượng chất phân tích thấp, tiến hành phân tích lặp lại 10 lần.LOD và LOQ được tính thông qua giá trị SD cho kết quả tương ứng trong khoảng 2,7-3,8 $\mu \mathrm{g} / 100 \mathrm{~g}$ và $9,1-12,6 \mu \mathrm{g} / 100 \mathrm{~g}$.

\subsection{3. Độ lạp lại, độ tái lập và độ đúng của phuong pháp}

Độ lặp lại của phương pháp được đánh giá bằng cách phân tích lặp lại 6 lần các nền mẫu thực phẩm dinh dưỡng (mẫu dạng bột, mẫu dạng lỏng, mẫu bột dinh dưỡng), tính độ lệch chuẩn RSDr\% và độ tái lập được đánh giá bằng cách phân tích lặp lại 4 lần với các nền mẫu trên, tính độ lệch chuẩn $\mathrm{RSD}_{\mathrm{R}} \%$

Độ đúng của phương pháp được xác định thông qua độ thu hồi. Trên các nền mẫu thực phẩm dinh dưỡng trên, tiến hành thêm chuẩn ở 3 mức khác nhau, tính độ thu hồi $\mathrm{R} \%$ 
Kết quả phân tích được thể hiện trong bảng 3 .

Bảng 3. Kết quả phân tích độ lập lại, độ tái lập, độ thu hồi của phurong pháp

\begin{tabular}{|c|c|c|c|c|}
\hline Tên Vitamin & Thông số khảo sát & Mẫu sĩa $a b \hat{o} t$ & Sũa dạng lỏng & Bột dinh duõng \\
\hline \multirow{3}{*}{ Vitamin B1 } & $\operatorname{RSD}_{\mathrm{r}} \%$ & 4,79 & 3,24 & 4,27 \\
\hline & $\mathrm{RSD}_{\mathrm{R}} \%$ & 5,79 & 5,71 & 5,09 \\
\hline & $\mathrm{R} \%$ & $85,8-105$ & $80,1-105$ & $82,1-103$ \\
\hline \multirow{3}{*}{ Vitamin B2 } & $\mathrm{RSD}_{\mathrm{r}} \%$ & 4,50 & 4,68 & 4,47 \\
\hline & $\mathrm{RSD}_{\mathrm{R}} \%$ & 7,19 & 9,66 & 7,10 \\
\hline & $\mathrm{R} \%$ & $88,6-106$ & $90,6-102$ & $90,0-107$ \\
\hline \multirow{3}{*}{ Vitamin B3 } & $\mathrm{RSD}_{\mathrm{r}} \%$ & 3,35 & 2,61 & 3,20 \\
\hline & $\mathrm{RSD}_{\mathrm{R}} \%$ & 4,70 & 5,09 & 3,40 \\
\hline & $\mathrm{R} \%$ & $89,9-105$ & $85,0-107$ & $83,4-95,2$ \\
\hline \multirow{3}{*}{ Vitamin B6 } & $\mathrm{RSD}_{\mathrm{r}} \%$ & 3,92 & 4,04 & 4,79 \\
\hline & $\mathrm{RSD}_{\mathrm{R}} \%$ & 4,49 & 9,69 & 4,81 \\
\hline & $\mathrm{R} \%$ & $84,6-106$ & $93,5-105$ & $90,6-103$ \\
\hline
\end{tabular}

\section{4. Đánh giá phương pháp phân tích trong một số mẫu thực tế}

Trên cơ sở đánh giá phương pháp đạt yêu cầu của AOAC, chúng tôi ứng dụng phương pháp để phân tích mẫu 15 mẫu thực phẩm dinh dưỡng thu thập trên thị trường Hà Nội. Kết quả được chỉ ra trong Bảng 4.

Bảng 4. Kết quả phân tích một số mẫu thực phẩm dinh duỡng

\begin{tabular}{|c|c|c|c|c|}
\hline Tên Vitamin & Thông số khảo sát & Mẫu sũa bột & Sũa dạng lỏng & Bột dinh duõng \\
\hline \multirow{3}{*}{ Vitamin B1 } & $\operatorname{RSD}_{r} \%$ & 4,79 & 3,24 & 4,27 \\
\hline & $\mathrm{RSD}_{\mathrm{R}} \%$ & 5,79 & 5,71 & 5,09 \\
\hline & $\mathrm{R} \%$ & $85,8-105$ & $80,1-105$ & $82,1-103$ \\
\hline \multirow{3}{*}{ Vitamin B2 } & $\mathrm{RSD}_{\mathrm{r}} \%$ & 4,50 & 4,68 & 4,47 \\
\hline & $\mathrm{RSD}_{\mathrm{R}} \%$ & 7,19 & 9,66 & 7,10 \\
\hline & $\mathrm{R} \%$ & $88,6-106$ & $90,6-102$ & $90,0-107$ \\
\hline \multirow{3}{*}{ Vitamin B3 } & $\mathrm{RSD}_{\mathrm{r}} \%$ & 3,35 & 2,61 & 3,20 \\
\hline & $\mathrm{RSD}_{\mathrm{R}} \%$ & 4,70 & 5,09 & 3,40 \\
\hline & $\mathrm{R} \%$ & $89,9-105$ & $85,0-107$ & $83,4-95,2$ \\
\hline \multirow{3}{*}{ Vitamin B6 } & $\mathrm{RSD}_{\mathrm{r}} \%$ & 3,92 & 4,04 & 4,79 \\
\hline & $\mathrm{RSD}_{\mathrm{R}} \%$ & 4,49 & 9,69 & 4,81 \\
\hline & $\mathrm{R} \%$ & $84,6-106$ & $93,5-105$ & $90,6-103$ \\
\hline
\end{tabular}

Kết quả cho thấy hàm lượng vitamin trong các mẫu thực phẩm dinh dưỡng dao động trong khoảng: $0,025-1,1 \mathrm{mg} / 100 \mathrm{~g}$ đối với vitamin $\mathrm{B} 1,0,09-2 \mathrm{mg} / 100 \mathrm{~g}$ đối với vitamin $\mathrm{B} 2$, $0,35-10 \mathrm{mg} / 100 \mathrm{~g}$ đối với vitamin $\mathrm{B} 3,0,08-0,87 \mathrm{mg} / 100 \mathrm{~g}$ đối với vitamin $\mathrm{B} 6$. Kết quả phân tích phù hợp với công bố trên nhãn sản phầm và có thể xác định được các dạng khác nhau của các vitamin ở hàm lượng thấp. 


\section{Kết luận}

Sử dụng phương pháp sắc ký lỏng khối phổ hai lần LC-MS/MS kết hợp với xử lý mẫu bằng phương pháp enzyme và sử dụng nội chuẩn đồng vị và tiến hành phân tích đồng thời cả chuẩn và mẫu phân tích để loại bỏ các yếu tố ảnh hưởng trong nền mẫu phân tích. Các kết quả thẩm định cho thấy phương pháp độ lặp lại, độ tái lập, độ thu hồi đều đạt yêu cầu của AOAC. Quy trình được ứng dụng để phân tích 15 mẫu thực phẩm dinh dưỡng (sữa bột, sữa dạng lỏng, bột dinh dưỡng). Phương pháp có độ nhạy, độ chính xác cao.

\section{TÀI LIỆU THAM KHẢO}

1. TCVN 5164:2008 (EN 14122:2014). Xác định vitamin $\mathrm{B} 1$ trong thực phẩm bằng phương pháp sắc ký lỏng hiệu năng cao.

2. TCVN 8975:2011(EN 14152:2014). Xác định vitamin $\mathrm{B} 2$ trong thực phẩm bằng phương pháp sắc ký lỏng hiệu năng cao.

3. TCVN 8976:2011(EN 14166:2009). Xác định vitamin $\mathrm{B} 6$ bằng phép thử vi sinh.

4. TCVN 9513:2012 (EN14663:2005). Phân tích vitamin B6 bao gồm dạng glycosyl bằng phương pháp sắc ký lỏng hiệu năng cao.

5. TCVN 9045: 2012 (EN 15652:2009). Tiến hành phân tích niacin trong thực phẩm bằng HPLC.

6. AOAC 2015.14.Total Vitamins B1, B2, B3 and B6 in Infant Formula and Related Nutrition alsEnzymatic Digestion and LC-MS/MS. AOAC International: Gaithersburg, MD, 2015.

7. AOAC 986.27. Thiamine (Vitamin B1 in Milk-Based Infant Formula); AOAC International: Gaithersburg, MD, 1986.

8. AOAC 985.31. Riboflavin in Ready-to-Feed Milk-Based Infant Formula. Fluorometric Method

9. AOAC Official Method 986.27 Thiamine (Vitamin B1) in Milk-Based Infant Formula. Fluorometric Method.

10. AOAC Official Method 975.41. Niacin and Niacinamide in Cereal Products. Automated method.

\section{Summary}

SIMULTANEOUS DETERMINATION SOME OF B GROUP VITAMINS IN

NUTRITIONAL PRODUCTS BY LIQUID CHROMATOGRAPHY TAMDEM MASS

SPECTROMETRY FOLLOWING ENZYMATIC HYDROLYSIS

\section{Le Thi Thuy', Vu Thi Trang ${ }^{I}$, Tran Hoang Giang ${ }^{I}$, Tran Mai Van ${ }^{2}$, Le Thi Hong Hao ${ }^{I}$ 'National Institute for Food Control \\ ${ }^{2}$ HaNoi Medical University}

Liquid chromatography tandem mass spectrometry (LC-MS/MS) method was developed for the simultaneous qualification of relevant forms of B group vitamins including vitamin B1, B2, $\mathrm{B} 3$ and $\mathrm{B} 6$ in nutritional products. Samples are hydrolyzed by enzymatic digestion at $37^{\circ} \mathrm{C}$ in the shaking water bath within approximately 12 to 14 hours. Papain and $\alpha$-amylase enzymes were used to hydrolize the protein and complex carbohydrate. Acid phosphatase was used to cut phosphoryl links to form free vitamin forms. The separation was achieved on a C18 column $(100 \mathrm{~mm} \times 2.1 \mathrm{~mm} \times 1.7 \mu \mathrm{m})$. Analytes were eluted with the mobile phase of $10 \mathrm{mM}$ ammonium formate and methanol by gradient program at a flow rate of $0.15 \mathrm{~mL} / \mathrm{min}$. The calibration curves ranged from 0.2 to $2000 \mathrm{ng} / \mathrm{mL}$ with the correlation coefficients $>0.998$. Limits of detection and quantification of method ranged from 2.7 to $3.8 \mu \mathrm{g} / 100 \mathrm{~g}$ and $9.1-12.6 \mu \mathrm{g} / 100 \mathrm{~g}$, respectively. The method was validated at three different concentrations with the recovery of $80-110 \%$, relative standard deviation of repeatability, RSDr \%, of $2.61-4.69 \%$, and intermediate reproducibility, $\mathrm{RSD}_{\mathrm{R}} \%$ of $3.40-9.69 \%$. The method was applied to simultaneously determine the four water soluble vitamins in several of nutritional products.

Keywords: Vitamin, LC-MS/MS, nutritional products 